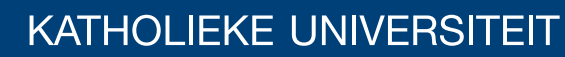 \\ LEUVEN
}

\section{Faculty of Business and Economics}

Measuring Scarcity in Agricultural Markets, 1900-2000: The Shifting Informativeness of Price v Storage Data

Katelijne A.E. Carbonez, Van Thi Tuong Nguyen, Piet Sercu

DEPARTMENT OF ACCOUNTANCY, FINANCE AND INSURANCE (AFI) 


\title{
Measuring Scarcity in Agricultural Markets, 1900-2000: The Shifting Informativeness of Price v Storage Data*
}

\author{
Katelijne A.E. Carbonez ${ }^{\dagger}$ \\ Van Thi Tuong Nguyen $\ddagger$ \\ Piet Sercu ${ }^{\S}$
}

Tuesday $2^{\text {nd }}$ March, 2010

\begin{abstract}
Kaldor (1939) and Working $(1948,1949)$ note that a commodity's backwardation is very much related to temporary scarcity. To them, the obvious measure of scarcity is the current level of inventories relative to a normal level. In 1987-2007 data, however, the spot price has become much more successful at explaining backwardation in agricultural markets (Carbonez, Nguyen and Sercu, 2010). This raises the question as to why Kaldor and Working did not bring up this measure, especially after the influential Hayek (1945) paper on the role of prices in market economies.

We hand-collect 1885-1935 data, which correspond much better to material that Working and Kaldor should have had access to. In those days, we find, prices were effectively less informative than in modern times, while inventories were more so. The declining relevance of storage data can plausibly be traced to the waning of Chicago as the main ag warehouse of the US., culminating in a new delivery system where the goods are represented by shipping receipts on a barge on the Illinois or Mississippi river rather than Chicago warehouse receipts.
\end{abstract}

JEL classification: G12, G14, G1, N32, N52, Q11

Key words: backwardation, convenience yield, theory of storage, scarcity

\footnotetext{
*We gratefully acknowledge financial support from FWO and ICM, and help with the data from the USDA. We also thank Pierre Six, Marno Verbeek and especially Michael Brennan and Philip Garcia for useful comments, and other participants at the 2008 Corporate Finance Day (Rotterdam), workshops at K.U.Leuven, UCLouvain, Université du Nord at Lille, and the University of Illinois, and the AFFI2008 International Meeting. All errors are the authors'. Forerunners to this paper were circulating under the name "Modeling Scarcity in Convenience Yield"

${ }^{\dagger} \mathrm{ICM} \mathrm{PhD}$ Fellow at Leuven School of Business and Economics, K.U.Leuven, Naamsestraat 69, B-3000 Leuven; +32 163266 59; Katelijne.Carbonez@econ.kuleuven.be

${ }^{\ddagger}$ FWO PhD Fellow at Leuven School of Business and Economics, K.U.Leuven, Naamsestraat 69, B-3000 Leuven; +32 163264 62; thituongvan.nguyen@econ.kuleuven.be

${ }^{\S}$ Leuven School of Business and Economics, K.U.Leuven, Naamsestraat 69, B-3000 Leuven; +32 16326756 ; Piet.Sercu@econ.kuleuven.be
} 


\section{Introduction and research question}

Kaldor (1939) and Working $(1948,1949)$ note that a commodity's backwardation — the premium the spot price commands over a futures price, after accounting for storage and interest costs - is very much related to temporary scarcity. To them, the obvious measure of scarcity is the current level of inventories relative to a normal level. In 1987-2007 data on agricultural markets, however, the spot price turns out to be much more successful at explaining backwardation (Carbonez, Nguyen and Sercu, 2010). This raises the question as to why Kaldor and Working did not bring up this measure, especially after the influential Hayek (1945) paper on the role of prices in market economies. We hand-collect 1885-1935 data, which correspond much better to material that Working and Kaldor should have had access to. In those days, we find, the informativeness of prices was much lower than in modern times, while that of storage data used to be much higher. Presumably, improved collection and distribution of information have played a role in boosting the performance of prices as summary measures of tightness or abundance. For the decline of the informativeness of inventory data, however, a more concrete explanation is available, viz the waning of Chicago as the main ag warehouse of the US., culminating in a new delivery system where the goods are represented by shipping receipts on a barge on the Illinois or Mississippi river rather than Chicago warehouse receipt. Below we provide more details on the Kaldor-Working view on backwardation, our research questions, and our findings.

Futures prices obviously reflect expectations about future demand and supply, while spot prices refer to current demand and supply. If both markets were unconnected, any temporary glut could occasionally result in spot prices that are much below futures prices, and vice versa. But current and future markets are effectively connected, albeit asymmetrically so. In case of a temporary glut, notably, arbitrageurs can step in, buying spot and selling forward. Any such storage decision reduces the current abundance and, instead, adds to future supply. The equilibrium amount of storage equals whatever is needed for the cost-adjusted spot price to stay in line with the futures price. The opposite type of arbitrage cannot happen, though: if there is a temporary shortage and inventories are low already, arbitrageurs cannot transfer future supply to the present, which means that abnormally high spot prices can emerge and persist.

In this view, then, the actions of intertemporal arbitrageurs ensure that the cost-adjusted spot-forward premium (or backwardation) should never fall to negative levels, not even in 
periods of abundance. But when markets are temporarily tight, the no-arb-from-storage bound ceases to be binding. This happens when the marginal spot buyers are not arbitrageurs but users. Even when the futures markets tell them that prices are expected to come down, users are willing to temporarily pay a premium for cash goods as long as the expected cost of running out of stock ${ }^{1}$ is worse than the premium they have to pay for cash raw materials. Holbrook Working famously called this benefit, which accrues to users that hold cash goods but not to arbitrageurs or holders of forward contracts, the 'convenience yield' of a cash position. One can think of the convenience yield as a non-monetary dividend that justifies a higher spot price, in the same way the foreign interest rate lifts a currency's spot value above the discounted forward rate. Summing up, then, we conclude that backwardation should be high when inventories are low, and fall gradually towards zero as stocks are higher — the 'Working curve'.

While the above logic is widely accepted, it is also true there are obvious practical problems with measuring inventories and, a fortiori, deviations from a 'normal' value. One way out is offered by the fact that low inventories, whether due to a spike in demand or a shortfall in production, should also be reflected in the spot price. In the literature, there is no consensus as to which indicator should work best. Brennan (1959), for instance, argues that time- $t$ inventory is an exact function of the current spot price; therefore the spot price should be an equally sufficient statistic for scarcity. Garcia and Good (1983) similarly assert that the convenience yield of corn is affected by the flow of corn to the market or by "the rate at which producers deliver corn to the market" and "the rate at which the market is consuming corn". They then argue that the current cash price is probably the best indicator of the corn flow to the market because it influences the storage and marketing decisions of the farmers and thus leads to relative shifts from demand to supply. But inventory remains quite popular, as reflected in the work by Telser (1958), Brennan (1958), Garcia and Good (1983), Karlson, Anderson and Dahl (1993), Yoon and Brorsen (2002), and Gorton, Hayashi and Rouwenhorst (2007). Some of these authors add additional variables, like time to maturity or, in the case of Fama and French (1987) a dummy reflecting the occurrence of a harvest during the contract's life, a proxy for both abundance/scarcity and time.

Carbonez, Nguyen and Sercu (2010), henceforth CNS, study agricultural goods (wheat, corn and soy) in the period 1986-2007, and compare the explanatory power of price and quantity

\footnotetext{
${ }^{1}$ Other related benefits, besides lower out-of-stock costs, are increased flexibility in production, and the option to time the market.
} 
data using a variety of regression specifications. In addition, they derive a new specification. First, they say, whether one uses prices or stocks as indicator of abundance, time to maturity matters too; in fact, there are separate roles for the total life of the contract and the part beyond an intervening harvest, if any. In addition, these duration variables should enter the equation not additively but multiplicatively, that is, as pure interactions with the scarcity function rather than as additional 'main' effects. This model effectively works much better than the simpler, more ad hoc ones. However, regardless of which functional form they use, prices always come out as the premier model if the choice is between price- and inventory-based models. While the combined variant, containing both price- and inventory-based variables, does even better, the pure-price model still emerges as a very close second.

While Hayek, for one, would not be surprised about this finding, one could still wonder why Working did not bring up price as a measure of scarcity, not even after the Hayek's influential 1945 Econometrica paper. Our answer is that, in Working's experience, prices seemed to deliver not nearly as good a job as did inventory data. In our historic data base and using a simple regression as available to early researchers, prices come a distant third in terms of explanatory power; in these regressions, the inventory model is the one coming at the heels of the combined model. Only by using the multiplicative formulation is the superior performance of prices visible in the old data. (In recent prices, it shows up in both specifications.)

Apart from solving the riddle of why Kaldor and Working propose quantity numbers not price, the historic sample is fascinating because there have been relevant changes in the characteristics of the data which can shed light on the question why, for instance, storage data do less well than before. The first difference between the pre-1936 and new data pertains to the role of Chicago, with implications for the interpretation of the inventory data. In the past, most of the warehouses were in Chicago, and all deliveries under futures contracts happened in Chicago. Later on also Toledo (on Lake Erie not Lake Michigan) became also acceptable, and nowadays delivery can be done on a whole list of barge mooring locations on the Illinois and Mississippi rivers; the buyer gets a shipping receipt rather than the warehouse receipts of old. A second (and related) difference is that inventory levels in Chicago used to account for a far higher proportion of nationwide totals than they do nowadays. In 1885-1935 the inventory held in Chicago accounted, on average, to $33 \%, 15 \%$ and $24 \%$ of the total visible supply in the US for corn, wheat and oats, respectively. In contrast, for the current period Chicago's share in countrywide visible supplies has dwindled to $1.3 \%$ for wheat and $7.2 \%$ for corn. A third difference is that the spot price in the older sample is conceivably of better quality than 
in the modern sample. Notably, the daily settlement price was set in an organized (and very liquid) exchange, the Chicago Board of Trade (Свот). Nowadays, delivery in Chicago is far rarer, and spot prices differ substantially depending on where delivery is asked. Datastream even cautions the user about the CBOT spot prices, and provides, as a substitute, averages of the prices paid by the Central Illinois Country Elevators to the producers, recorded during the afternoons. Academics often use the nearest futures price as a stand-in for the spot price. For these reasons, the historic Chicago data are much closer to the textbook view of a market, i.e. a single-location one. The CNS results provide strong indications that the traditional stock data are now less relevant than in Working's days: they seem to be either too narrow (Chicago), or too aggregated (Great Lakes or nationwide) in the sense that these wider aggregates ignore location issues. Thus, past data can help tell us whether the increased locational issues are behind the decline of the informativeness of inventories.

The remainder of this article is structured as follows. Section 1 reviews the standard models and discuss the CNS multiplicative model. Section 2 compare empirical results between the traditional and multiplicative models for the historic sample to answer our research question. In this section, we also verify whether the splines obtained from the multiplicative model have the shape of "Working curves". Section 3 concludes.

\section{Modeling convenience yield and current scarcity}

In this section we review the traditional test equations and the CNS model. Strictly speaking, our characterization of futures prices applies to forward prices only, but the two are now recognized to be virtually undistinguishable.

Backwardation is defined as:

$$
Y_{t, T}:=\underbrace{\left[S_{t}+\operatorname{PV}(C, \mathbf{r}, t, T)\right]\left(1+r_{t, T}\right)}_{\text {total time- } T \text { cost of buy-and-store }}-f_{t, T}
$$

where $t$ denotes current time (the moment of valuation) and $T$ the moment the futures contract expires; $Y_{t, T}$ is the backwardation, i.e. the net premium paid for cash positions; $S_{t}$ the current spot price; $\mathrm{PV}(C, \mathbf{r}, t, T)$ the present value of paying the storage cost $C$ over the contract's life; $r_{t, T}$ the simple percentage rate of return on a risk-free investment maturing at $T$; and $f_{t, T}$ the current futures price. When $Y$ is positive, the market is said to be 'in (normal) backwardation'; negative $Y$ s mean the market is 'in contango', a situation regarded as anomalous, as we shall see. 
Since Kaldor (1939) and Working $(1948,1949)$, most of the literature tests the Net Convenience Yield theory by verifying whether $Y_{t, T}$ is related to time- $t$ inventory. The typical finding is that there is, in fact, a convex negative relationship (the "Working curve") between the inventory level and the convenience yield, as expected under the theory of storage. Still, prices could provide additional information and could even subsume the insights obtained from inventory data. Thus, one can distinguish between inventory-only models, price-only models, and combined models. As of now, inventory will be denoted by $x_{t}$, and spot prices by $S_{t}$. Within the class of inventory models, some researchers like Garcia and Good (1983) and Karlson, Anderson and Dahl (1993) adopt concise functions like $a+b x$ or $a+b \ln x$ or $a+b x^{-1}$. Telser (1958), Brennan (1958), Yoon and Brorsen (2002), and Gorton, Hayashi and Rouwenhorst (2007) take multi-term nonlinear functions. Among these, the spline inventory function applied by Gorton et al. is the most flexible one; it surely captures the time series and term structure of backwardation better than the others:

$$
\text { (Inv model: }) Y_{t, T}=\alpha+\theta_{1} x_{t}+\theta_{2} x_{t}^{2}+\theta_{3} x_{t}^{3}+\theta_{4} \mathbf{1}_{x_{t}>k}\left(x_{t}-k\right)^{3} \text {. }
$$

where $x_{t}$ is inventory, and $\mathbf{1}_{x_{t}>k}=1$ if $\left(x_{t}>k\right)$, otherwise $\mathbf{1}_{x_{t}>k}=0$. Within this class of models we use just the best performing one, a spline in normalized inventory; normalization (here, division by a Hodrick-Prescott trend) makes the economic interpretation of quantities more comparable over time.

At the other extreme, one could follow Hayek and argue that the ultimate summary statistic for scarcity should be the price. As the current spot price $S_{t}$ is already used to compute backwardation, we work with the lagged spot price. We also deflated $S_{t}$ by the CPI to enhance comparability of data over time and to steer clear of unit roots in the time series. One can of course include both $S$ and $x$, the combined model.

Lastly, traditional models often include a time-to-maturity term (for instance, Jiang and Hayenga, 1997), or the timing within the year (Fama and French, 1987). As the traditional $x$-spline and the combined models are systematically beaten by their variants that include duration, we report the latter versions only. Thus, our traditional-model line-up looks as follows:

$$
\begin{aligned}
(\text { Spot }) & : Y_{t, T}=\alpha+\beta S_{t-1} \\
(\mathrm{I}+\mathrm{TTM}) & : Y_{t, T}=\alpha+\theta_{1} x_{t}+\theta_{2} x_{t}^{2}+\theta_{3} x_{t}^{3}+\theta_{4} \mathbf{1}_{x_{t}>k}\left(x_{t}-k\right)^{3}+\gamma(T-t) \\
(\mathrm{S}+\mathrm{I}+\mathrm{TTM}) & : Y_{t, T}=\alpha+\beta S_{t-1}+\theta_{1} x_{t}+\theta_{2} x_{t}^{2}+\theta_{3} x_{t}^{3}+\theta_{4} \mathbf{1}_{x_{t}>k}\left(x_{t}-k\right)^{3}+\gamma(T-t)
\end{aligned}
$$

The relative parsimony of the price model is hardly loading the dice in favor of the storage 
model: unlike for quantity data, higher powers of prices do not add meaningful explanatory power. At any rate, this paper looks at shifts over time and not so much at comparative performances across models. Lastly, recall that we find that price models do win; so, experimenting with richer spot-price models could only have reinforced that conclusion and can never reverse it.

We now proceed to the alternative specification proposed by CNS. Their model starts from a more formal argument, which here is summarized verbally. Suppose purchase managers think in periods - weeks, for instance. Their current desired inventory will consist of expected consumption for the coming week, plus a safety stock. The cost of shifting forward the purchase of a small quantity $\mathrm{d} Q$, i.e. buying an extra $\mathrm{d} Q$ now instead of next week, is equal to the current spot price (plus storage and interest cost over one week), minus the risk-adjusted expected spot price next week. This last item is the shadow one-week futures price, and the marginal cost of shifting inventory forward is, accordingly, a shadow one-week backwardation, denoted by $y_{t, t+1}$. In the optimum, the shadow one-week backwardation equals the expected savings, during the next week, from the last bit of safety stock, and those savings are non-negative.

To link this to a multi-period backwardation, CNS express the shadow one-week futures price as the expectation of the spot price two weeks out, the cost of carry in the second week, and second week's marginal convenience. Repeated substitution like this leads to an expression where the backwardation in a contract with a life of $n$ weeks consists of the sum of all the week-by-week expected convenience yields, $\mathrm{E}_{t}^{q}\left(y_{t+s, t+s+1}\right)$, each capitalized towards time $T$. Now if the term structure of weekly conveniences would be flat, the capitalized final value of an $n$-week payment over a life of a few weeks would be well approximated by its simple sum. CNS show that this remains true if weekly convenience yields are expected to rise geometrically at a moderate rate, because this growth can be absorbed into the interest rate and because over short lives interest rates do not matter so much. Thus, the capitalized final value of $n$ weeks of convenience is approximately its initial weekly level, times time to maturity: $Y_{t, T} \approx y_{t, t+1} \cdot(T-t)$-as long as week-by-week marginal backwardation is expected to rise smoothly.

That smoothness condition is violated if there is a harvest during the contract's life: at $T_{h}$, fresh supplies make the backwardation drop discretely, and a new path is expected to start from that lower level. To correct for this, CNS write the total backwardation as:

$$
Y_{t, T} \approx y_{t, t+1} \cdot(T-t)+\mathrm{E}_{t}^{q}\left(y_{T_{h}, T_{h}+1}\right) \cdot \max \left(T-T_{h}, 0\right)
$$


Both of the one-week convenience yields, the current one and the expected post-harvest one, can be modeled as functions of current inventory, the current spot, or both. CNS adopt a spline, but in $x^{-1}$ rather than in $x$ itself because the inverse is much better at capturing a strongly convex relation.

There is one last twist to the CNS model. They show that published inventory data systematically peak not at the time of harvest, but months later. This, CNS conjecture, shows that initially the harvested goods remain in silos near the fields rather than being immediately shipped to Chicago. But market prices see through the under-reported quantities: backwardation drops, reflecting the true availabilities in the neighborhood of Chicago. To neutralize systematic seasonal errors in reported storage data, CNS add monthly dummies, whose coefficients can correct for the average gap between reported and true storage. Thus, the final 'multiplicative' models are:

$$
\begin{aligned}
(\mathrm{S} \times \mathrm{TTM}): Y_{t, T}=\alpha & +\left(\sum_{m=1,12} \delta_{m} \mathbf{1}_{M(t)=m}+\beta S_{t-1}\right) \cdot(T-t) \\
& +\left(\sum_{m=1,12} \rho_{m} \mathbf{1}_{M(t)=m}+\zeta S_{t-1}\right) \cdot \max \left(T-T_{h}, 0\right), \\
(\mathrm{I} \times \mathrm{TTM}): Y_{t, T}=\alpha & +\left(\sum_{m=1,12} \delta_{m} \mathbf{1}_{M(t)=m}+f\left(x_{t}\right)\right) \cdot(T-t) \\
& +\left(\sum_{m=1,12} \rho_{m} \mathbf{1}_{M(t)=m}+g\left(x_{t}\right)\right) \cdot \max \left(T-T_{h}, 0\right), \\
Y_{t, T}=\alpha & +\left(\sum_{m=1,12} \delta_{m} \mathbf{1}_{M(t)=m}+\beta S_{t-1}+f\left(x_{t}\right)\right) \cdot(T-t) \\
(\mathrm{S}+\mathrm{I} \times \mathrm{TTM}) & \left(\sum_{m=1,12} \rho_{m} \mathbf{1}_{M(t)=m}+\zeta S_{t-1}+g\left(x_{t}\right)\right) \cdot \max \left(T-T_{h}, 0\right),
\end{aligned}
$$

where both $f(x)$ and $g(x)$ are spline functions in the inverse of $x$,

$$
\begin{aligned}
& f\left(x_{t}\right)=a_{1} x_{t}^{-1}+a_{2} x_{t}^{-2}+a_{3} x_{t}^{-3}+a_{4} \mathbf{1}_{x_{t}^{-1}>k_{1}}\left(x_{t}^{-1}-k_{1}\right)^{3}, \\
& g\left(x_{t}\right)=b_{1} x_{t}^{-1}+b_{2} x_{t}^{-2}+b_{3} x_{t}^{-3}+b_{4} \mathbf{1}_{x_{t}^{-1}>k_{1}}\left(x_{t}^{-1}-k_{1}\right)^{3} .
\end{aligned}
$$

We now proceed to the empirical work on the historic sample, 1885-1935, the type of data Kaldor and Working must have been familiar with. 


\section{Empirical results from the historic sample}

As stated, the first reason for using older data is that this would allow us to replicate and extend older studies about the theory of storage, like Kaldor (1939), Working (1948), Telser (1958), Brennan (1958). We have hand-collected almost 50 years of weekly data, from 1/1/1885 to $31 / 12 / 1935$, an unique data set in this field as far as we know. Equally important, tests on earlier data can provide valuable insights for comparison because the environment has changed non-trivially. As expounded in the introduction, the pre-1936 spot prices are, arguably, of better quality in that they are set in an organized, liquid exchange and refer to delivery in Chicago, where substantial part of the country's inventories were being kept. Nowadays, inventories in Chicago have dwindled, in relative terms; and spot prices for Chicago differ erratically from those in Toledo and from the averages of wholesale purchase prices arranged bilaterally in the fields - problems that prompted CNS to substitute the nearest futures price for the elusive theoretical spot rate. ${ }^{2}$ But in the historic period we can effectively use spot prices. In addition, Chicago the representativeness and validity of the historic inventory data is less of an issue.

Less relevantly for this study, the pre-1936 records contain data that are potentially relevant but are no longer published, like weekly shipment and receipt data in Chicago, spot prices for a whole range of qualities (deliverable and other), and storage costs. For instance, the data for different qualities allow tests of whether quality aggregation creates spurious Workinglike patterns. There are a few more differences that are just technical. One concerns the forward shifting in the harvest period that happened after WW2. Another technical difference between the pre-1936 and new data relates to the number of delivery months and the lengths of contracts' lives. Prior to 1936, May-June-September-December were the most common dates, and the maximum life was at most 11 months. Since then, more expiry months have been added, and contracts start trading more than a year before expiry. For the pre-1936 data we use data from May-June-September-December contracts, which have all been consistently present and were well-traded.

\footnotetext{
${ }^{2} \mathrm{CNS}$ report that their conclusions remain unaffected if other spot-price proxies are used, like average elevator prices.
} 


\section{$2.1 \quad$ Data}

Data for the inventory, the spot price, the futures price and the storage cost come from microfilms provided by The Chicago Board of Trade (Свот), and from the Свот help desk for the many cases where the microfilms were too unclear to read. We exclude data from 9/1917 to $7 / 1920$ because trading restrictions and price ceilings were in place in the aftermath of the first World war. We use the Consumer Price Index (CPI) from the NBER to deflate our price data. The interest rate is also from NBER. The daily spot and futures prices are the average of the daily highest and lowest price quoted in Chicago. We do not include the maturity month of the contract in our analysis because the delivery date is not fixed precisely and because the liquidity of a futures contract is very low in its delivery month.

\section{Model selection and data preprocessing}

To compare the competing models we consider the adjusted- $R^{2}$, the Akaike information criterion $(A I C)$ and the Schwarz or Bayesian information criterion $(B I C)$. In addition, we also apply the P-test proposed by Davidson and Mackinnon (1981) (henceforth referred to as DM test) for simultaneously testing the truth of a model (the base model) against several non-nested models. DM's P-test is a standard likelihood-ratio test of the hypothesis that alternative models add nothing once the fitted-value predictions from the base model is taken into account. $P$ statistic is asymptotically Chi-squared distributed with degrees of freedom equal to the number of alternative non-nested models if the base model is true. Thus, an insignificantly low $P$ statistic says that the base model may very well be the true one.

Inventory data must be compared to normal levels before we can see whether they signal a tight market or not. In this study, normalized inventory equals inventory divided by its Hodrick-Prescott trend. Visual inspection suggested a smoothness parameter of $8 \mathrm{E}+8$. After correction for frequency, this corresponds to a cycle between 10 and 30 years. ${ }^{3}$

For the second main regressor, prices, the hypothesis of a unit root is acceptable for all

\footnotetext{
${ }^{3}$ The recommended smoothness parameter, $\lambda_{q}$, in quarterly series is 1,600 for peak-to-peak cycles of short duration (roughly 10 year), and 160,000 for cycles of about 30 years or longer. Gorton et al. (2007), for instance, use 160,000. To translate $\lambda_{q}$ into an equivalent for weekly data, Ravn and Uhlig (2002) recommend multiplication by the fourth power of the relative frequency. Taking 4 weeks in a month, we would get $\lambda_{w}=$ $\lambda_{q} \times 12^{4}=\lambda_{q} \times 20,736$, implying an equivalent quarterly smoothness of $\lambda_{q}=38,500$-in-between the 1600 and 160,000 standards. Eviews' default option is to multiply by the square of the relative frequency instead of the fourth power. This provides a much lower smoothness, and led to a trend that totally overfits the series.
} 
Table 1: Number of observations for each contract from 1/1885 to 12/1935

\begin{tabular}{lccc}
\hline Contract & Wheat & Corn & Oats \\
\hline May & 1727 & 1763 & 1786 \\
July & 1436 & 1391 & 1287 \\
September & 1224 & 1251 & 1152 \\
December & 1181 & 1150 & 992 \\
\hline
\end{tabular}

three series. Fortunately, it turns out that simple deflation by the CPI takes care of the unit root: the Phillips-Perron test probabilities under the null of a unit root for the deflated price series are $1.18 \%$ for corn, $6.77 \%$ for soybeans and $8.63 \%$ for wheat. Deflation makes sense on economic grounds too: deflating prices implicitly also deflates the convenience yields; so a dollar paid for convenience is corrected for the near-doubling of the CPI over the entire period.

Instead of splicing together data for the shortest available contract into a single time series, we use data for all parallel contracts offered on a given date. Indeed, we note that, in the multiplicative model, all commodity futures prices, regardless of their delivery date, are driven by the same term structure of expected one-period convenience yields. If CNS's assumption holds that this term structure is either sloping upward or downward with, possibly, a jump at harvest time, then the same function $f() \cdot(T-t)+g() \cdot \max \left(T-T_{h}, 0\right)$ should fit all contracts. Thus, we apply pooled estimation for the new models with the restriction that the currentscarcity coefficients in $f()$ and $g()$ are the same for all contracts. For the traditional models, in contrast, we let the impact of spot prices and time to maturity (TTM) vary across contracts (cross section specific coefficients). All models are estimated using Pooled Least Squares with fixed effects and correcting for period Heteroscedasticity and Serial Correlation (Period SUR), which corrects for serial correlation and heteroscedasticity in the residuals of a given crosssection. Table 1 describes the number of observations for each contract of each commodity.

\subsection{Results for the historic sample}

Table 2 highlights the most obvious finding as far as the shifts are concerned between the historic database and the new one (CNS). It shows, for both periods, the $R^{2} \mathrm{~s}$, averaged across the three commodities, for each of the six models. i.e. the traditional and the multiplicative specifications, each coming in a spot, inventory and combined version. The detailed results 
Table 2: Comparisons of average $R^{2}$ s for multiplicative and traditional models, 1885-1935 versus 1986-2007

\begin{tabular}{lcccccc} 
& \multicolumn{3}{c}{ Traditional models } & \multicolumn{3}{c}{ multiplicative models } \\
\cline { 3 - 7 } & Spot & $\mathrm{I}+\mathrm{TTM}$ & $\mathrm{S}+\mathrm{I}+\mathrm{TTM}$ & $\mathrm{S} \times \mathrm{TTM}$ & $\mathrm{I} \times \mathrm{TTM}$ & $\mathrm{S}+\mathrm{I} \times \mathrm{TTM}$ \\
\hline Historic & 34.6 & 45.6 & 60.7 & 60.7 & 51.2 & 64.6 \\
Recent & 43.9 & 31.0 & 67.5 & 70.8 & 30.5 & 71.6 \\
\hline
\end{tabular}

Note:

1. The table summarizes results on convenience yields from six models: the traditional models for spot price (Spot), for inventory/time-tomaturity additive (I+TTM), for spot price and inventory (S+I+TTM) and the multiplicative models for spot price (s $\times$ TTM), for inventory/timeto-maturity additive (IXTTM), for spot price and inventory (S+IXTTM) for the historic sample from $1 / 1885$ to $12 / 1935$ for corn, wheat and oats.

$$
\begin{array}{rll}
\text { (Spot) } & : & Y_{t, T}=\alpha+\beta S_{t-1}, \\
(\mathrm{I}+\mathrm{TTM}) & : & Y_{t, T}=\alpha+\theta_{1} x_{t}+\theta_{2} x_{t}^{2}+\theta_{3} x_{t}^{3}+\theta_{4} \mathbf{1}_{x_{t}>k}\left(x_{t}-k\right)^{3}+\gamma(T-t), \\
(\mathrm{S}+\mathrm{I}+\mathrm{TTM}) & : & Y_{t, T}=\alpha+\beta S_{t-1}+\theta_{1} x_{t}+\theta_{2} x_{t}^{2}+\theta_{3} x_{t}^{3}+\theta_{4} \mathbf{1}_{x_{t}>k}\left(x_{t}-k\right)^{3}+\gamma(T-t), \\
(\mathrm{S} \times \mathrm{TTM}) & : & Y_{t, T}=\alpha+\left(\sum_{t=1}^{12} \delta_{m} \mathbf{1}_{M(t)=m}+\beta S_{t-1}\right) \cdot(T-t)+\left(\sum_{t=1}^{12} \rho_{m} \mathbf{1}_{M(t)=m}+\zeta S_{t-1}\right) \cdot \max \left(T-T_{h}, 0\right), \\
(\mathrm{I} \times \mathrm{TTM}) & : & Y_{t, T}=\alpha+\left(\sum_{t=1}^{12} \delta_{m} \mathbf{1}_{M(t)=m}+f\left(x_{t}\right)\right) \cdot(T-t)+\left(\sum_{t=1}^{12} \rho_{m} \mathbf{1}_{M(t)=m}+g\left(x_{t}\right)\right) \cdot \max \left(T-T_{h}, 0\right), \\
(\mathrm{S}+\mathrm{I} \times \mathrm{TTM}) & : & Y_{t, T}=\alpha+\left(\sum_{t=1}^{12} \delta_{m} \mathbf{1}_{M(t)=m}+\beta S_{t-1}+f\left(x_{t}\right)\right) \cdot(T-t)+\left(\sum_{t=1}^{12} \rho_{m} \mathbf{1}_{M(t)=m}+\zeta S_{t-1}+g\left(x_{t}\right)\right) \cdot \max \left(T-T_{h}, 0\right) .
\end{array}
$$

norminv is normalized inventory with long-term trend of more than 30 years (smoothness parameter of $1.05 \mathrm{~b}$ ). $\mathbf{1}_{x}>k_{1}=1$ if $n o r m i n v>k_{1}$, otherwise $\mathbf{1}_{x>k_{1}}=0$ for (I+TTM) and ( $\left.\mathrm{S}+\mathrm{I}+\mathrm{TTM}\right) . \mathbf{1}_{x>k_{2}}=1$ if $1 /$ norminv $>k_{2}$, otherwise $\mathbf{1}_{x>k_{2}}=0$ for ( $\times$ TTM), (I $\times \mathrm{TTM}$ ), and ( $+\mathrm{I} \times \mathrm{TTM}$ ). 2. In this table, $k_{1}=2.5$ and $k_{2}=10$ for all three commodities.

3 . For corn, the harvest time in this sample starts from 1 Oct, thus $T-T_{h}=240$ for for the May; 300 for the July; 360 for the September and 90 for the December contract. For wheat, the harvest time in this sample starts from 1 June, thus $T-T_{h}=360$ for the May; 60 for the July; 120 for the September and 210 for the December contract. For oats, the harvest time in this sample starts from 1 July, thus $T-T_{h}=330$ for the May; 30 for the July; 90 for the September and 180 for the December contract.

4. $P$ - statistic is the P test statistic based on the DM test to simultaneously compare one model with other non-nested models. ${ }^{* * *}, * *$ and *indicate the significant coefficients at $1 \%, 5 \%$ and $10 \%$ consecutively.

per commodity, and the numbers for the information criteria and the DM P-test are discussed later. Clearly, the explanatory power of pure price-based models, whether traditional or multiplicative, as shot up by some 10 percent, from 34 to 44 for the conventional specification, and from 60 to 70 in the alternative version. Pure inventory-based models, in contrast, have massively lost explanatory power, by 15 to 20 percent (from 46 to 31 in the additive version, 51 to 31 in the multiplicative one). The combined models follow the lead of the best models and have gained explanatory power over time. Interestingly, in the multiplicative version, the runner-up is the pure price model, with inventory as a very distant third. In the traditional specification, however, it's the other way around. Using graphical inspection, as Kaldor and Working did, or standard regressions, as the early econometricians did, there was no way to detect the interaction between scarcity and time, and the natural conclusion would be that inventory data are most informative.

Table 3 provides all four diagnostics separately per commodity and per regression rather than just $R^{2}$ s averaged across three goods. First, it can be checked that $R^{2}$ s do provide the correct signal: higher explanatory power always comes with lower AIC/BIC values and lower DM P-values. A second finding is that for each type of scarcity measure and for all commodities without any exception, the multiplicative regression always outperforms the corresponding 
Table 3: Comparisons of multiplicative models to traditional models for corn, soybeans and wheat for historic sample 1885-1935

\begin{tabular}{|c|c|c|c|c|c|c|}
\hline & \multicolumn{6}{|c|}{ Panel A: Corn } \\
\hline & \multicolumn{3}{|c|}{ Traditional models } & \multicolumn{3}{|c|}{ multiplicative models } \\
\hline & Spot & $\mathrm{I}+\mathrm{TTM}$ & $\mathrm{S}+\mathrm{I}+\mathrm{TTM}$ & $\mathrm{S} \times \mathrm{TTM}$ & IXTTM & $\mathrm{S}+\mathrm{I} \times \mathrm{TTM}$ \\
\hline$R^{2}(\%)$ & 32.41 & 50.62 & 61.32 & 61.61 & 56.60 & 65.81 \\
\hline$A I C$ & 6.106 & 5.813 & 5.548 & 5.542 & 5.687 & 5.427 \\
\hline$B I C$ & 6.115 & 5.827 & 5.567 & 5.573 & 5.724 & 5.468 \\
\hline \multirow[t]{4}{*}{$P-$ statistic } & 6050 & 2837 & 1224 & 1133 & 1862 & 353 \\
\hline & \multicolumn{6}{|c|}{ Panel B: Wheat } \\
\hline & \multicolumn{3}{|c|}{ Traditional models } & \multicolumn{3}{|c|}{ multiplicative models } \\
\hline & Spot & $\mathrm{I}+\mathrm{TTM}$ & $\mathrm{S}+\mathrm{I}+\mathrm{TTM}$ & $\mathrm{S} \times \mathrm{TTM}$ & $\mathrm{I} \times \mathrm{TTM}$ & $\overline{\mathrm{S}+\mathrm{I} \times \mathrm{TTM}}$ \\
\hline$R^{2}(\%)$ & 40.61 & 36.80 & 58.47 & 58.45 & 43.57 & 63.46 \\
\hline$A I C$ & 6.686 & 6.741 & 6.329 & 6.332 & 6.632 & 6.205 \\
\hline$B I C$ & 6.695 & 6.755 & 6.349 & 6.367 & 6.672 & 6.250 \\
\hline \multirow[t]{4}{*}{$P-$ statistic } & 4062 & 4696 & 1253 & 1216 & 3588 & 452 \\
\hline & \multicolumn{6}{|c|}{ Panel C: Oats } \\
\hline & \multicolumn{3}{|c|}{ Traditional models } & \multicolumn{3}{|c|}{ multiplicative models } \\
\hline & Spot & $\mathrm{I}+\mathrm{TTM}$ & $\mathrm{S}+\mathrm{I}+\mathrm{TTM}$ & $\mathrm{S} \times \mathrm{TTM}$ & $\mathrm{I} \times \mathrm{TTM}$ & $\mathrm{S}+\mathrm{I} \times \mathrm{TTM}$ \\
\hline$R^{2}(\%)$ & 30.70 & 49.45 & 62.16 & 62.07 & 53.52 & 64.40 \\
\hline$A I C$ & 5.281 & 4.989 & 4.678 & 4.683 & 4.909 & 4.621 \\
\hline$B I C$ & 5.292 & 5.004 & 4.699 & 4.719 & 4.952 & 4.668 \\
\hline \multirow[t]{4}{*}{$P-$ statistic } & 5992 & 2964 & 1042 & 1153 & 2329 & 661 \\
\hline & \multicolumn{6}{|c|}{ Panel D: $R^{2}$ s from Modern Data (1986-2007) } \\
\hline & \multicolumn{3}{|c|}{ Traditional models } & \multicolumn{3}{|c|}{ multiplicative models } \\
\hline & Spot & $\mathrm{I}+\mathrm{TTM}$ & $\mathrm{S}+\mathrm{I}+\mathrm{TTM}$ & $\mathrm{S} \times \mathrm{TTM}$ & $\mathrm{I} \times \mathrm{TTM}$ & $\mathrm{S}+\mathrm{I} \times \mathrm{TTM}$ \\
\hline Corn & 52.38 & 32.59 & 73.65 & 78.21 & 32.91 & 78.31 \\
\hline Wheat & 48.74 & 29.44 & 70.55 & 75.79 & 30.58 & 76.02 \\
\hline Soybeans & 30.65 & 30.95 & 58.21 & 58.28 & 28.12 & 60.40 \\
\hline
\end{tabular}

Note: See preceding table

traditional model. Thus, the CNS findings do not seem to be a fluke based on a quirk in recent data. Third, the combined model does best, of course; but in the multiplicative version it is the spot-price variant that works better than the pure quantity-based version, again providing independent support for the earlier CNS findings. In fact, the price model's distance from the premier version is always smaller than the lead the price model has relative to the inventory model. Thus, our recommendation for any time-traveling hedgers and practitioners would still be valid: using the multiplicative model, the spot price can be used to capture the convenience yield quite well. Fourth, and more interesting to economist with a historic interest, an additive model would have led us believe that the inventory-based model beats the price-based version in two cases out of three (corn and oats), and with quite a decent lead; for wheat, the exception, the spot-price model leads, but only narrowly so. Thus, as what we had guessed from the averages, it seems that a combination of linear analysis or graphical inspection and some quirk in the data has hidden the richness of the price data. These results help to understand the Working-Kaldor focus on quantity data in the past.

The change over time in the relevance of storage data is not visible only via $R^{2}$ s and the 
Figure 1: Estimated monthly dummies from models I×TTM and S×TTM: 1/1885-12/1935

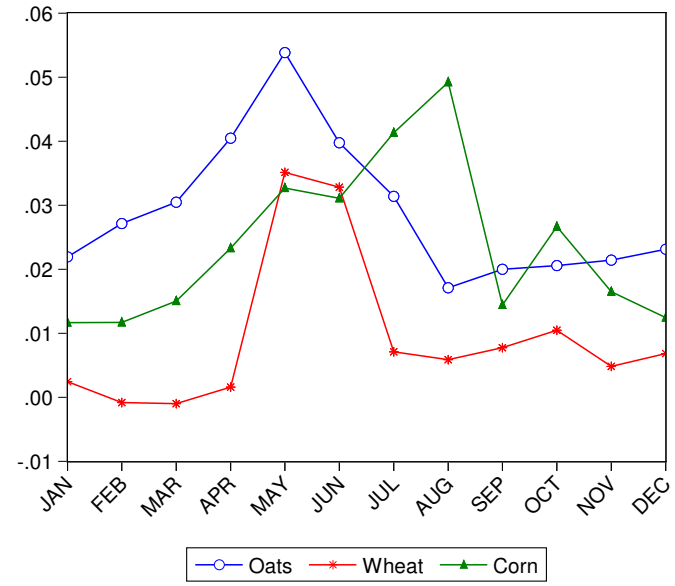

(a) $\mathrm{I} \times \mathrm{TTM}$

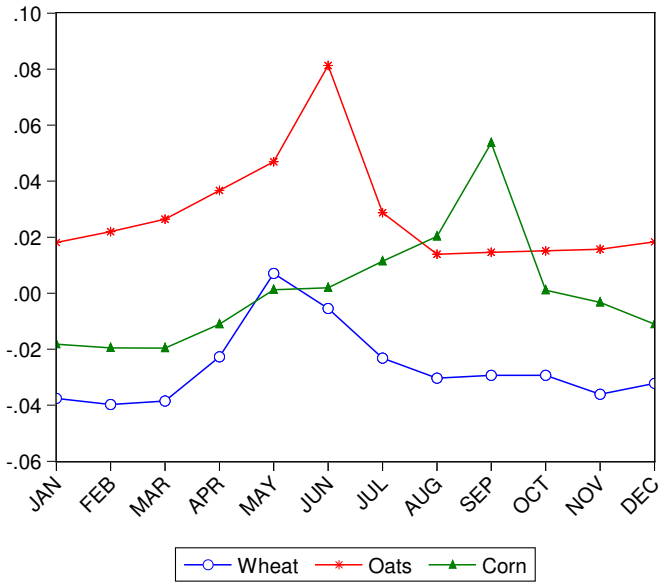

(b) $\mathrm{S} \times \mathrm{TTM}$

Note: In these graph, we plot the dummy coefficients that interact with Tтм in model I×Tтм (Equation 8 ) and $\mathrm{S} \times$ TTM (Equation 7 ).

like. There is also some interesting circumstantial evidence. Specifically, when we inspect the seasonal dummies in panels (a) and (b) of Figure 1, we no longer observe the clear pattern of downward corrections right after the harvest like in the current period. This fits in with the idea that the quality of inventory data was better. Still, the seasonal dummies often remain significant; combined with the absence of an obvious interpretation, this remains a bit of a puzzle.

By way of diagnostic check, we add flow variables; given the data, we can use not only changes of inventories but also shipments into and out of Chicago. They were not significant. And, unsurprisingly, we still obtain the negative and convex relation between yields and storage data, as Figure 2 shows. For these graphs we have set time to maturity equal to 365 days; the contracts shown are September for corn, and May for wheat and oats. Because in this period the corn September contract has $T-T_{h}$ equal 360, the set TTM gives 5 days for the period beyond the harvest for corn. These numbers are 5 for wheat and 35 for oats. The parameters are shown in the appendix tables, along with the estimates from the pared-down estimations where only significant terms are kept of the inventory multiplicative model (I $\times$ TTM, pruned). 
Figure 2: Convenience yield-inventory curve for wheat, corn, oats 1/1885 - 12/1935

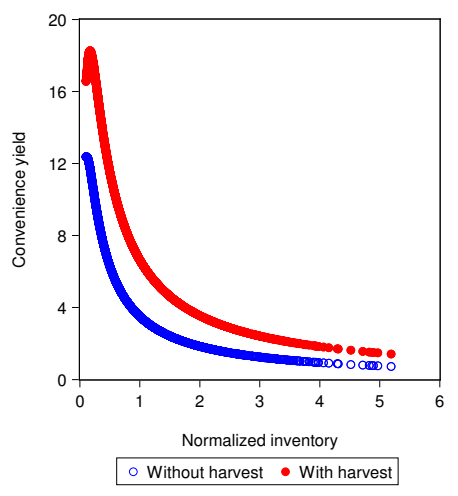

(a) Corn

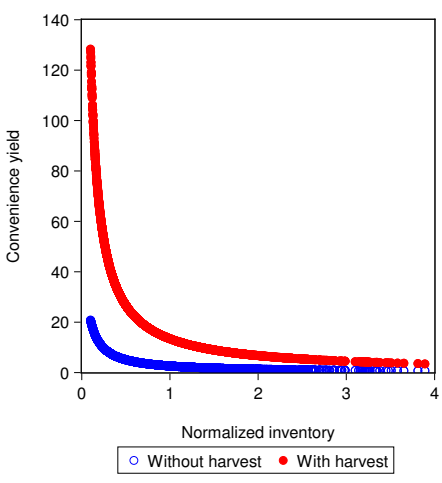

(b) Wheat

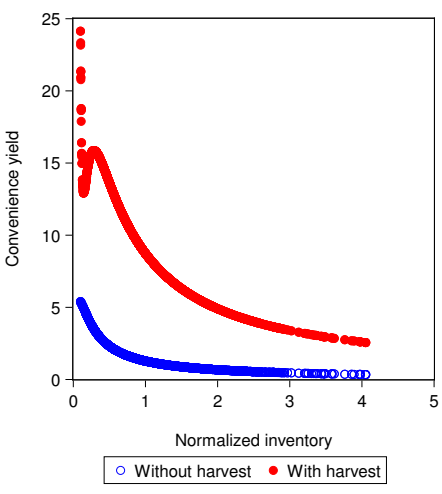

(c) Oats

Note: The graphs show the fitted value of the convenience yields based on Equation (8) with the pooled estimation results. The graphs are split by commodity (corn, wheat or oats) for the pre-1936 period. In one graph, there are two curves: (i) for contracts mature before the harvest time (without harvest); (ii) for after the harvest time (with harvest).

\section{Conclusion}

Why has most of the literature on backwardation and the theory of storage focused on quantity data? Our answer is that, in conventional regressions, prices used to do a poor job at explaining backwardation. A recent researcher would have concluded that things have shifted recently in favor of prices, which now lead storage data by a similar margin as inventory used to enjoy in the old days. Only when a less ad hoc multiplicative model is used does the systematic superiority of prices become evident. Still, even in that specification, storage data have been demoted from an honorable third position to a dismal third one, while the explanatory power of prices has shot up even in absolute terms rather than just relative to its contender.

It is probably non-controversial that improved collection and distribution of information have helped markets in setting prices more efficiently. For the decline of the informativeness of inventory data, however, a more concrete explanation is available, viz the waning of Chicago as the main commodity warehouse of the US. Chicago used to be the dominant warehousing location, and the sole delivery point for futures contracts. Nowadays, Chicago's share in storage is minute; and Toledo or, nowadays, even barges on the Mississippi and Illinois rivers, have become delivery points. With the definition of the product becoming increasingly fuzzy in terms of location, there seems to be no obvious choice as to the best level of aggregation for data: Chicago, the states Illinois and Ohio, the Great Lakes, or the country as a whole. Prices, it seems, are doing a reasonably good job at looking through that mist. 
Measuring Scarcity in Agricultural Markets, 1900-2000

\section{References}

Benirschka, Martin and James K. Binkley. (August, 1995). "Optimal Storage and Marketing over Space and Time." American Journal of Agricultural Economics Association. 77:512-524.

Brennan, D., J.C. Williams and B.D. Wright. (1997). "Convenience Yield without the Convenience: A Spatial-Temporal Interpretation of Storage under Backwardation." Economics Journal. 107:1009-1022.

Brennan, M.J. (1958). "The Supply of Storage." American Economics Review. 47:50-72.

Brennan, M.J. (April, 1959). "A Model of Seasonal Inventories." Econometrica. 27(2):228-244.

Bruce Bjornson and Colin A. Carter. (August, 1997). "New Evidence on Agricultural Commodity Return Performance under Time-Varying Risk." American Journal of Agricultural Economics. 79(3):918-930.

Carsten Sorensen. (1999). "Seasonality in Agricultural Commodity Futures." EFA 0689; EFMA 2000 Athens.

Carter, C., Rausser, G., Schmitz,A. (1983). "Efficient Asset Portfolio and The Theory of Normal Backwardation." Journal of Political Economy. 91:319-331.

Chang, E.C.(1985). "Returns to Speculators and the Theory of Normal Backwardation." Journal of Finance. 40:193-208.

Chavas, Jean-Paul, Paula M. Despins, and T. Randy Fortenbery. (May, 2000). "Inventory Dynamics Under Transaction Costs." American Journal of Agricultural Economics. 82:260-273.

Colin A. Carter and Cesar L. Revoredo Giha. (November, 2007). "The Working Curve and Commodity Storage under Backwardation." American Journal of Agricultural Economics. 89(4):864-872.

Daniel S. Tilley and Steven K. Campbell. (November, 1988). "Performance of The Weekly GulfKansas City Hard-Red Winter Wheat Basis." American Journal of Agricultural Economics. 70(4):929-935.

Davidson R. and James G. MacKinnon. (May, 1981). "Several Tests for Model Specification in the Presence of Alternative Hypotheses." Econometrica. 49(3):781-793.

Deaton, A. and Laroque, G. (January, 1991). "On the Behavior of Commodity Prices." Review of Economics Studies.59:1-23.

Dusak, K. (1973). "Futures Trading and Investor Returns: An Investigation of Commodity Market Risk Premiums." Journal of Political Economy. 81:1387-1406.

Fama, E.F., and K.R.French. (1987). "Commodity Futures Prices: Some Evidence on Forecast Power, Premiums, and the Theory of Storage." The Journal of Business. 60(1):55-73.

Frechette, Darren L. and Paul L. Fackler. (November, 1999). "What Causes Commodity Price Backwardation." American Journal of Agricultural Economics. 81:761-771.

Garcia, P. and D. Good. (1983). "Analysis of Factors Influencing Illinois Regional Corn Basis, 197181." Proceeding of the NCR-134 Conference on Applied Commodity Price Analysis, Forecasting and Risk Management. 306-326.

Hartzmark, M.L. (1987). "Returns to Individual Traders of Futures: Aggregate Results." Journal of Political Economy. 95:1292-1306.

Hayek, F. von (1945). "The Use of Knowledge in society." American Economic Review 35(4), 5-16

Irwin, S.H.; Garcia, P.; Good, D.L. and Kunda, E.L. (2008) 'Recent Convergence Performance of CBOT Corn, Soybean and Wheat Futures Contracts', Choices, 23: 16-21.

Irwin, S.H.; Sanders, D.R. and Merrin, R.P. (2008) 'Devil or Angel: The Role of Speculation in the Recent Commodity Price Boom (and Bust)' Working paper, uiuc, 27p. 
Jiang, Bingrong and Martin Hayenga. (1997). "Corn and Soybean Basis Behavior and Forecasting: Fundamental and Alternative Approaches." Proceeding of the NCR-134 Conference on Applied Commodity Price Analysis, Forecasting and Risk Management. Chicago, IL.

Kaldor, N. (July, 1939). "Speculation and Economic Stability." Review Economics Studies. 1-27.

Keynes, J.M. (1930). "A Treaties on Money." New York: Harcourt. 2.

Gary B. Gorton, Fumio Hayashi and K. Geert Rouwenhorst. (July, 2007). "The Fundamentals of Commodity Futures Returns." NBER Working Paper No. W13249.

Nail, Gopal and Raymond M. Leuthold. (1991). "A Note on the Factors Affecting Corn Basis Relationships." Southern Journal of Agricultural Economics. 147-153.

Nicholas Karlson, Brad Anderson and Reynold Dahl. (January, 1993). "Cash-Futures Price Relatiohship: Guides to Corn Marketing." Staff Paper P93-1, Department of Agricultural and Applied Economics, University of Minnesota.

Paul H. Cootner. (August, 1690). "Returns to Speculators: Telser versus Keynes." The Journal of Political Economy. 68(4):396-404.

Ronald W. Ward and Frank A. Dasse. (February, 1997). "Empirical Contributions to Basis Theory: The Case of Citrus Futures." American Journal of Agricultural Economics. 59(1):71-80.

Telser, L. (June, 1958). "Futures Trading and the Storage of Cotton and Wheat." Journal of Political Economy. 66:233-255.

Thompson, S. (1986). "Returns to Storage in Coffee and Cocoa Futures Markets." Journal of Futures Markets. 6(Winter):541-564.

Victor K. Ng and Stephen Craig Pirrong. (April, 1994). "Fundamental and Volatility: Storage, Spreads and the Dynamics of Metal Prices." Journal of Business. 67(2):203-230.

Working, H. (1948). "Theory of the Inverse Carrying Charge in Futures Markets." Journal of Farm Economics. 30:1-28.

Working, H. (December, 1949). "The Theory of the Price of Storage." American Economics Review. 39:1254-1262.

Wright, Bryan D. and Jeffrey C. Williams. (February, 1989). "A Theory of Negative Prices for Storage." The Journal of Futures Markets. 9(1):1-13.

Yoon, Byung-Sam and B. Wade Brorsen. (2002). "Market Inversion in Commodity Futures Prices." Journal of Agricultural and Applied Economics. 34(3):451-476. 


\section{Appendix Table}

Table 4: Estimation results for corn, wheat and soybeans for the historic sample 1885-1935

\begin{tabular}{|c|c|c|c|c|c|c|}
\hline & \multicolumn{2}{|c|}{ Panel A: Corn } & \multicolumn{2}{|c|}{ Panel B: Wheat } & \multicolumn{2}{|c|}{ Panel C: Oats } \\
\hline & $\mathrm{S}+\mathrm{I} \times \mathrm{TTM}$ & $\mathrm{I} \times \mathrm{T}$, pruned & $\mathrm{S}+\mathrm{I} \times \mathrm{TTM}$ & $\mathrm{I} \times \mathrm{T}$, pruned & $\mathrm{S}+\mathrm{I} \times \mathrm{TTM}$ & $\mathrm{I} \times \mathrm{T}$, pruned \\
\hline Alpha-may & -0.69 & -0.88 & -1.04 & -0.67 & -1.35 & -1.10 \\
\hline Alpha $-j u l$ & -0.69 & -0.55 & 0.66 & 0.47 & 0.02 & 0.07 \\
\hline Alpha-sep & -0.71 & -0.46 & 0.90 & 0.66 & 1.79 & 1.62 \\
\hline Alpha-dec & 2.65 & 2.52 & -0.22 & -0.27 & 0.33 & -0.00 \\
\hline $\begin{array}{l}(T-t) * \text { spot } \\
\left(T-T_{h}\right) * \text { spot }\end{array}$ & $\begin{array}{l}7.1 e-4^{\text {*w* }} \\
9.6 e-4^{\text {*** }}\end{array}$ & & $\begin{array}{r}4.2 e-4^{\text {*w* }} \\
0.003^{\text {**** }}\end{array}$ & & $\begin{array}{c}1.4 e-4 \\
0.003^{\text {*ate }}\end{array}$ & \\
\hline$(T-t) * x 1$ & $0.008^{\text {*we }}$ & $0.011^{\text {*⿻丷木 }}$ & $0.007^{\text {*w* }}$ & $0.007^{\text {*wak }}$ & $0.003^{\text {*we }}$ & $0.004^{\text {*wa }}$ \\
\hline$(T-t) * x 2$ & $-8.8 e-4^{\text {*w* }}$ & $-0.001^{\text {*w* }}$ & $-2.4 e-4$ & $-1.7 e-4^{\text {*ak }}$ & $-2.6 e-4^{* *}$ & $-3.5 e-4^{\text {*at }}$ \\
\hline$(T-t) * x 3$ & $3.1 e-5^{\text {*wk }}$ & $3.9 e-5^{* * k}$ & $4.7 e-6$ & $1.3 e-6^{\text {*tok }}$ & $8.5 e-6^{* *}$ & $1.2 e-5^{\text {*ow }}$ \\
\hline$(T-t) * x 4$ & $-3.2 e-5^{\text {*w* }}$ & $-4.0 e-5^{* * k}$ & $-3.8 e-6$ & & $-8.5 e-6^{* *}$ & $-1.2 e-5^{\text {*k* }}$ \\
\hline$\left(T-T_{h}\right) * x 1$ & 0.004 & $0.010^{* *}$ & $-0.023^{\text {*wok }}$ & $0.030^{\text {*we }}$ & $0.018^{\text {*tek }}$ & $0.029^{* * *}$ \\
\hline$\left(T-T_{h}\right) * x 2$ & $-8.4 e-4^{* *}$ & $-0.002^{\text {*wk }}$ & $0.007^{\text {*t* }}$ & & $-0.004^{\text {*atk }}$ & $-0.007^{* * * k}$ \\
\hline$\left(T-T_{h}\right) * x 3$ & $4.1 e-5^{* *}$ & $7.5 e-5^{\text {*w* }}$ & $-3.5 e-4^{* k}$ & & $2.9 e-4^{\text {*ak }}$ & $4.5 e-4^{* 2 k}$ \\
\hline$\left(T-T_{h}\right) * x 4$ & $-5.5 e-5^{\text {*we }}$ & $-9.5 e-5^{\text {*ak }}$ & $-5.9 e-5$ & $-6.3 e-4^{* \text { *o }}$ & $-0.002^{\text {*ek }}$ & $-0.003^{* * k}$ \\
\hline$(T-t) * J a n$ & $-0.020^{\text {** }}$ & $0.012^{* * k}$ & $-0.026^{\text {** }}$ & 0.004 & 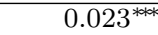 & $0.022^{\text {*w* }}$ \\
\hline$(T-t) * F e b$ & $-0.020^{\text {*wek }}$ & $0.012^{\text {*owk }}$ & $-0.029^{* *}$ & 0.001 & $0.027^{\text {*at }}$ & $0.027^{\text {*wo }}$ \\
\hline$(T-t) * M a r$ & $-0.017^{* *}$ & $0.015^{\text {*ow }}$ & $-0.028^{* *}$ & 0.001 & $0.032^{\text {*⿻*k }}$ & $0.030^{\text {*w* }}$ \\
\hline$(T-t) * A p r$ & -0.008 & $0.023^{\text {*** }}$ & -0.017 & 0.004 & $0.043^{\text {*⿻大从t }}$ & $0.040^{\text {*w* }}$ \\
\hline$(T-t) * M a y$ & $6.5 e-4$ & $0.033^{\text {*t*k }}$ & 0.012 & 0.004 & $0.056^{\text {*⿻大从t }}$ & $0.054^{\text {*** }}$ \\
\hline$(T-t) *$ Jun & $5.1 e-4$ & $0.031^{\text {*owk }}$ & $8.4 e-4$ & 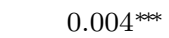 & $0.093^{\text {*tat }}$ & $0.040^{*}$ \\
\hline$(T-t) * J u l$ & 0.010 & $0.041^{\text {*at* }}$ & $-0.024^{*}$ & 0.009 & $0.029^{\text {*⿻大k }}$ & $0.031^{\text {*a* }}$ \\
\hline$(T-t) * A u g$ & 0.018 & $0.049^{\text {*owk }}$ & $-0.023^{*}$ & $0.008^{* *}$ & $0.016^{* *}$ & $0.017^{\text {*aw }}$ \\
\hline$(T-t) * S e p$ & 0.021 & 0.014 & $-0.021^{*}$ & $0.010^{\text {*w* }}$ & $0.018^{* * k}$ & 0.020 \\
\hline$(T-t) * O c t$ & -0.006 & $0.027^{\text {*ow }}$ & $-0.019^{*}$ & $0.013^{\text {*owk }}$ & $0.019^{\text {*tak }}$ & $0.021^{\text {*a* }}$ \\
\hline$(T-t) * N o v$ & -0.015 & $0.016^{\text {*wo }}$ & $-0.025^{* *}$ & 0.007 & $0.020^{\text {*** }}$ & $0.021^{\text {*** }}$ \\
\hline$(T-t) * D e c$ & $-0.018^{\text {** }}$ & $0.012^{\text {*t*k }}$ & $-0.021^{*}$ & 0.009 & $0.023^{\text {*wek }}$ & $0.023^{\text {*w* }}$ \\
\hline$\left(T-T_{h}\right) *$ Jan & & & $-0.147^{\text {*wk }}$ & $0.070^{\text {*w* }}$ & $-0.097^{\text {*ak }}$ & 0.015 \\
\hline$\left(T-T_{h}\right) * F e b$ & & & $-0.155^{* * k}$ & $0.052^{\text {*** }}$ & $-0.106^{\text {*ate }}$ & -0.006 \\
\hline$\left(T-T_{h}\right) * M a r$ & & & $-0.171^{\text {*1*k }}$ & $0.030^{*}$ & $-0.109^{* *+k}$ & -0.010 \\
\hline$\left(T-T_{h}\right) * A p r$ & $-0.045^{*}$ & 0.013 & $-0.191^{\text {*** }}$ & 0.020 & $-0.121^{\text {*ate }}$ & $-0.029^{* *}$ \\
\hline$\left(T-T_{h}\right) *$ May & $-0.046^{*}$ & 0.011 & $-0.230^{* * * k}$ & -0.025 & $-0.137^{\text {*tek }}$ & $-0.045^{* * *}$ \\
\hline$\left(T-T_{h}\right) *$ Jun & $-0.061^{\text {*we }}$ & -0.004 & $-0.248^{\text {*ak }}$ & $-0.065^{\text {*ak }}$ & $-0.184^{*+1 \times k}$ & -0.028 \\
\hline$\left(T-T_{h}\right) * J u l$ & $-0.067^{* \text { *k* }}$ & -0.011 & & & $-0.119^{\text {*ak }}$ & $-0.034^{* \alpha *}$ \\
\hline$\left(T-T_{h}\right) * A u g$ & $-0.080^{\text {*ak }}$ & $-0.032^{*}$ & & & & \\
\hline$\left(T-T_{h}\right) * S e p$ & $-0.081^{\text {** }}$ & 0.005 & $-0.137^{\text {*ow }}$ & $0.084^{\text {*a* }}$ & & \\
\hline$\left(T-T_{h}\right) * O c t$ & $-0.054^{\text {*ak }}$ & $-0.013^{* *}$ & $-0.095^{*}$ & $0.103^{\text {*k }}$ & -0.018 & $0.083^{\text {*wok }}$ \\
\hline$\left(T-T_{h}\right) * N o v$ & & & $-0.112^{* *}$ & $0.090^{\text {*ak }}$ & $-0.077^{\text {*ath }}$ & $0.020^{*}$ \\
\hline$\left(T-T_{h}\right) * D e c$ & & & $-0.154^{* * *}$ & $0.052^{\text {*k }}$ & $-0.078^{\text {*ak }}$ & $0.024^{*}$ \\
\hline
\end{tabular}

Note:

1. The table provides the detail estimation results from the proposed model for spot price and inventory (S+I $\times$ TTM) and the ' $\mathrm{I} \times \mathrm{T}$, pruned' which is based on the $\mathrm{I} \times \mathrm{T}$ but only the significant terms for inventory are kept for the historic sample from $1 / 1885$ to $12 / 1935$.

$$
\begin{aligned}
(\mathrm{I} \times \mathrm{TTM}) & : \quad Y_{t, T}=\alpha+\left(\sum_{t=1}^{12} \delta_{m} \mathbf{1}_{M(t)=m}+f\left(x_{t}\right)\right) \cdot(T-t)+\left(\sum_{t=1}^{12} \rho_{m} \mathbf{1}_{M(t)=m}+g\left(x_{t}\right)\right) \cdot \max \left(T-T_{h}, 0\right), \text { with } x=1 / \text { norminv }, \\
(\mathrm{S}+\mathrm{I} \times \mathrm{TTM}) & : \quad Y_{t, T}=\alpha+\left(\sum_{t=1}^{12} \delta_{m} \mathbf{1}_{M(t)=m}+\beta S_{t-1}+f\left(x_{t}\right)\right) \cdot(T-t)+\left(\sum_{t=1}^{12} \rho_{m} \mathbf{1}_{M(t)=m}+\zeta S_{t-1}+g\left(x_{t}\right)\right) \cdot \max \left(T-T_{h}, 0\right) .
\end{aligned}
$$

norminv is normalized inventory with long-term trend of more than 30 years (smoothness parameter of $0.8 \mathrm{~b}$ ). $\mathbf{1}_{x>k_{2}}=1$ if $1 /$ norminv $>k_{2}$, otherwise $\mathbf{1}_{x>k_{2}}=0$.

2. In this table, $k_{2}=10$ for all three commodities.

3. For corn, the harvest time in this sample starts from 1 Oct, thus $T-T_{h}=240$ for for the May; 300 for the July; 360 for the September and 90 for the December contract. For wheat, the harvest time in this sample starts from 1 June, thus $T-T_{h}=360$ for the May; 60 for the July; 120 for the September and 210 for the December contract. For oats, the harvest time in this sample starts from 1 July, thus $T-T_{h}=330$ for the May; 30 for the July; 90 for the September and 180 for the December contract.

4. $P$-statistic is the $\mathrm{P}$ test statistic based on the DM test to simultaneously compare one model with other non-nested models. ${ }^{* * *}$, ** and *indicate the significant coefficients at $1 \%, 5 \%$ and $10 \%$ consecutively. 